\title{
Gender Occupational Segregation in an Equilibrium Search Model*
}

\author{
Emiko Usui ${ }^{\dagger}$ \\ Nagoya University and IZA
}

\begin{abstract}
This paper develops an equilibrium search model to explain gender asymmetry in occupational distribution. Workers' utility depends on salary and working hours, and women have a greater aversion to market hours than men. Simulations indicate that women crowd into shorter-hour, lower-paying jobs than men. If employers discriminate against women, offers are tailored more toward men's preferences; employers require longer working hours, and fewer women work at these jobs. Similarly, if women have a disutility factor in their utility toward positions with a higher proportion of men, fewer women work at these jobs. In both cases, gender segregation is reinforced.
\end{abstract}

JEL Classification: E24; J16; J64; J71.

Keywords: Equilibrium Search; Gender preferences; Employer discrimination; Employee discrimination.

${ }^{*}$ I thank Joseph Altonji, Rebecca Blank, Kerwin Charles, Hanming Fang, Ryo Kambayashi, Dale Mortensen, Tsunao Okumura, Jee-Hyeong Park, Randal Watson, and the participants from Nagoya University, the National Graduate Institute for Policy Studies, Osaka University, the University of Michigan, the University of Tokyo, Yale University, the Search Theory Workshop, the Japanese Economic Association, and the Society of Labor Economists Meeting for their helpful comments and suggestions. All errors are my own. This research is supported by JSPS grant 22000001.

${ }^{\dagger}$ Emiko Usui, School of Economics, Nagoya University, Nagoya, 464-8601, Japan. Tel: +81-45-789-4940; fax: +81-45-789-4924. E-mail address: usui@soec.nagoya-u.ac.jp. 


\section{Introduction}

Earnings and the number of hours worked vary considerably between men and women in the labor market. Women work in occupations that require shorter hours and pay lower wages, whereas men tend to work in longer-hour, higher-paying jobs.

Pioneered by Bergmann (1974), the overcrowding model shows that women "crowd" into certain occupations, which depresses their wages. ${ }^{1}$ Extending Bergmann's model, Johnson and Stafford (1998) provide a simple framework for understanding the factors that affect occupational gender segregation. Their analysis shows that women overcrowd into occupations with the following features: a smaller degree of employer discrimination exists; women prefer the job characteristics; women have a comparative advantage; and/or there is less social pressure. These models are based on a perfectly competitive labor market, where the labor supply curve facing an individual firm is perfectly elastic. However, if there are search frictions and workers have imperfect information regarding alternative job opportunities, a reduction in job value will not result in a loss of all employees to employers. Furthermore, empirical studies find that many workers are not perfectly matched to jobs with their desired working hours and that those who report dissatisfaction with their hours change employers to work in positions that are more in line with their preferred hours (Altonji and Paxson 1988; Kahn and Lang 1992; 1995; 2001). ${ }^{2}$

The purpose of this paper is to present a search model that explains the observed occupational asymmetries between men and women. I present a model based on the heterogeneousworkers, heterogeneous-firms version of the Burdett and Mortensen (1998) and Bontemps et al. (1999) wage-posting games. ${ }^{3}$ Relative to these papers, my model differs in the following two dimensions. First, the utility that a worker derives from a job does not necessarily coincide with the salary. It also depends on a non-pecuniary characteristic, which I consider to be the number of hours worked. This setup is similar to Hwang et al. (1998) and Lang and Majumdar (2004) in that it includes a job attribute other than salary. ${ }^{4}$ Therefore, instead of

\footnotetext{
${ }^{1}$ See Altonji and Blank (1999) for a comprehensive survey of the theoretical and empirical literature on gender occupational segregation.

${ }^{2}$ Altonji and Paxson (1986) and Senesky (2005) find that the variance of the change in hours worked is much higher for job movers than for job stayers. This finding implies that employers place significant constraints on their employees' choice of hours worked and that job movers are less constrained in their choice of hours worked than job stayers.

${ }^{3}$ The wage-posting model explains a number of stylized facts. For instance, wages are dispersed, and larger firms offer higher wages.

${ }^{4}$ Hwang et al. (1998) present a Burdett-Mortensen model where heterogeneous employers who differ in the production technology of job amenities post a tied-salary/amenity offer to homogenous workers. In contrast,
} 
a wage-posting game, my model is a job-posting game where every firm posts a single "tiedsalary/hours offer" that workers may accept or reject depending upon their status. Hours of work is also an important determinant for the demand side of the labor market because the flow output per employee (labor productivity) is not constant, as in Burdett and Mortensen (1988), but increases along with the total hours worked. Second, there is heterogeneity of workers across gender, which is modeled by a preference "shifter" in the disutility of work between males and females. Women are more reluctant to work longer market hours because, for instance, they spend more time producing household commodities. ${ }^{5}$ This fact is the main assumption behind the different labor market behaviors of men and women.

The equilibrium of this job-posting game is analyzed numerically. I find the following results:

1. There is a positive correlation between the number of hours worked and salary. Employers that are more productive require longer hours and offer higher salaries. This prediction is in accordance with the compensating differentials theory of Rosen (1974). Hours and salary correlate positively because the disamenity of the former "compensates" for the utility of the latter. For a given salary level, men experience a smaller disamenity to working, and more productive firms can profit from requiring longer hours. Thus, more productive firms hire men because men require smaller salary compensation for the long hours than women. Therefore, in equilibrium, men sort into longer-hour, higher-paying jobs, and women sort into shorter-hour, lower-paying jobs.

2. If employers experience disutility from hiring women, as in the model of taste-based discrimination à la Becker (1971), segregation is reinforced. Employers endogenously choose to post job offers with longer working hours to dissuade women (who are averse to long hours of work) from accepting these jobs. This strategy compensates employers for the utility loss from hiring women.

3. If women experience disutility from working in jobs with a higher fraction of men (em-

Lang and Majumdar (2004) consider a nonsequential model where homogenous employers make a take-it-orleave-it tied-salary/hours offer and trade off the salary/hours package against the possibility that the offer may be rejected.

${ }^{5}$ Using the U.S. Panel Study of Income Dynamics, Usui (2009) finds that the probability of reporting overemployment is higher for women than for men. Following Ham (1982; 1986), Altonji and Paxson (1988), and Kahn and Lang $(1992 ; 1995 ; 2001)$, Usui creates the overemployment measure by utilizing variables that indicate constraints against workers' hours on the job. 
ployee discrimination), the implications for segregation are the same as in (2). ${ }^{6}$ The difference is the channel: because the women experience lower utility in longer-hour jobs, they either prefer to remain unemployed or "coordinate" with other women in shorter-hour jobs. In response, employers tailor their job offerings to men to maintain their employment size.

The paper proceeds as follows. Section 2 sets up the model and presents the algorithm to compute the equilibrium tied-salary/hours offer. Section 3 presents the simulation results. The paper concludes in Section 4 .

\section{The Model}

Consider a scenario with a large, fixed number of employers and workers (men and women who are equally productive). The measure of men and women in the population is $n^{m}$ and $n^{f}$, respectively, and the measure of employers is normalized to 1 . Workers search for jobs while unemployed and employed, and employers offer job opportunities. Workers maximize their expected present value of utility by deciding which jobs to accept, and employers maximize their profits.

An employer's job offer to a worker consists of salary $S$ and hours of work $H$. Because anti-discrimination policies prohibit employers from making gender-specific offers, employers post only a single salary-hours combination that workers must accept unless no production takes place. ${ }^{7}$ Output per employee is a concave function of the worker's hours worked, denoted as $\rho_{j}(H)$ for a type- $j$ job, where $\rho_{j}(0)=0, \rho_{j}^{\prime}(H)>0$, and $\rho_{j}^{\prime \prime}(H)<0$ for all $j$. There is a continuous distribution of productivity across employers, and higher-productivity jobs have a larger marginal productivity of hours worked for any given level of hours.

Workers value a job based on its salary and working hours. The utility of a job for a worker whose gender is $g$ ( $m$ for men and $f$ for women) is

$$
v^{g}\left(S, H ; \xi^{g}\right)=S+\xi^{g} \phi(H),
$$

\footnotetext{
${ }^{6}$ There is empirical evidence that women care about the fraction of their co-workers who are female. According to job satisfaction data from the U.S. National Longitudinal Survey of Youth, women who move to jobs where there are more men report that co-workers are less friendly and that their physical surroundings are less pleasant, whereas men report the opposite (Usui 2008).

${ }^{7}$ Alternatively, Usui (2002) presents an equilibrium search model where employers can condition job offers by gender. This model is a simple extension of Hwang et al. (1998) because profit-maximizing employers post separate offers for men and women. Consequently, there is no need for employers to consider the difference between gender preferences or the mix of men and women who choose their jobs.
} 
where $\phi^{\prime}(H)<0$, and $\phi^{\prime \prime}(H)<0$. For simplicity's sake, it is assumed that $S$ and $H$ enter additively into workers' utility functions and that their marginal (dis)utilities are independent of one another. The parameter $\xi^{g}$ measures the degree of aversion to hours worked which is assumed to be

$$
0<\xi^{m}<\xi^{f}
$$

Therefore, the marginal disutility of working hours is greater for women than for men. ${ }^{8}$

Unemployed workers receive a utility flow $b$. Its distribution in the population (denoted by $K)$ is identical for men and women and is continuous on its support $(\underline{b}, \bar{b})$.

Example: Numerical simulations are used to derive the results in Section 3, and the functional forms for $\rho_{j}(H)$ and $v^{g}\left(S, H ; \xi^{g}\right)$ are specified as follows:

$$
\begin{gathered}
\rho_{j}(H)=-a_{j}(H-T)^{2}+a_{j} T^{2}, \\
v^{g}\left(S, H ; \xi^{g}\right)=S-\frac{\xi^{g}}{T-H},
\end{gathered}
$$

where $0 \leq H<T$ and $a_{j}>0$. The technology parameter $a_{j}$ ranges from $\underline{a}$ to $\bar{a}$.

\section{Discrimination}

Two types of discrimination are incorporated into the model. The first is employer discrimination, where employers have distaste $d^{E R}$ for hiring women. In this case, the employer's utility per female worker is $\rho_{j}(H)-S-d^{E R} \cdot{ }^{9}$

The second type is employee discrimination, where women have a disutility factor in their utility toward working with men. Specifically, women incur a disamenity value for working at jobs with a higher proportion of males. Denote $d^{E E}(\theta)$ as the utility loss for women, where $\theta$

is the fraction of men working in a job, and $\frac{\partial d^{E E}(\theta)}{\partial \theta}<0$. Then the women's utility for a job is $S+\xi^{f} \phi(H)-d^{E E}(\theta)$.

\section{Steady-State Stocks and Flows}

Workers sample a job offer (at rate $\lambda$ ) from a known distribution while unemployed or

\footnotetext{
${ }^{8}$ Alternatively, $H$ can represent the "effort" that an employee puts into the job. Effort increases productivity, and effort is more costly for female employees than for male employees. Gneezy et al. (2003) provide experimental evidence that men exert more effort than women in high-stakes situations.

${ }^{9}$ Employer discrimination in the framework of search models has been studied by Black (1995), Bowlus and Eckstein (2002), and Flabbi (2010).
} 
employed. The distribution of job values is given by functions $F^{m}$ for men and $F^{f}$ for women. Employed workers face job separation with an arrival rate of $\delta$.

The following results, as proposed in Bontemps et al. (1999), are well known for the worker's optimal job acceptance strategy. When unemployed, the optimal strategy is to accept all jobs that have a value greater than or equal to the reservation utility, which is simply $b$ because the arrival rate of job offers is independent of the worker's current state (i.e., employed or unemployed). When employed, the optimal strategy is to accept all jobs that have a greater value than the current job.

Let $u^{g}\left(x \mid F^{g}\right)$ denote the steady-state measure of unemployed workers whose reservation utility is less than or equal to $x$, conditional on the utility distribution of job offers $F^{g}$. Then

$$
u^{g}\left(x \mid F^{g}\right)=\int_{\underline{b}}^{x}\left(\frac{\delta n^{g}}{\delta+\lambda\left[1-F^{g}(b)\right]}\right) d K(b),
$$

because the unemployment rate of workers with a utility flow of $b$ is $\frac{\delta}{\delta+\lambda\left[1-F^{g}(b)\right]},{ }^{10}$ and the density of these workers is $n^{g} d K(b)$.

Let $G^{g}$ be the distribution of job values for employed workers. Then the steady-state measure of employed workers receiving utility no greater than $v^{g}$ is $G^{g}\left(v^{g}\right)\left\{n^{g}-u^{g}\left(\bar{b} \mid F^{g}\right)\right\}$, where $u^{g}\left(\bar{b} \mid F^{g}\right)$ is the total measure of unemployed workers in the economy. Because the flow of workers leaving jobs offering a utility no greater than $v^{g}$ (to unemployment or to highervalued jobs) equals the flow of workers entering such jobs from unemployment in a steady state,

$$
\left\{\delta+\lambda\left[1-F^{g}\left(v^{g}\right)\right]\right\} G^{g}\left(v^{g}\right)\left\{n^{g}-u^{g}\left(\bar{b} \mid F^{g}\right)\right\}=\lambda \int_{\underline{b}}^{v^{g}}\left[F^{g}\left(v^{g}\right)-F^{g}(x)\right] d u^{g}\left(x \mid F^{g}\right),
$$

where $d u^{g}\left(b \mid F^{g}\right)$ is the measure of unemployed workers with reservation utility $b$, and $\left[F^{g}\left(v^{g}\right)-F^{g}(b)\right]$ is the probability that an offer received by a worker with reservation utility $b$ is acceptable and less than or equal to $v^{g}$. This result yields

$$
G^{g}\left(v^{g}\right)\left\{n^{g}-u^{g}\left(\bar{b} \mid F^{g}\right)\right\}=\frac{\kappa \int_{\underline{b}}^{v^{g}}\left[F^{g}\left(v^{g}\right)-F^{g}(x)\right] d u^{g}\left(x \mid F^{g}\right)}{1+\kappa\left[1-F^{g}\left(v^{g}\right)\right]},
$$

where $\kappa=\lambda / \delta$ is the ratio of the job-offer arrival rate to the job separation rate. Let $l^{g}\left(v^{g}, F^{g}\right)$ represent the steady-state number of workers available to an employer offering $v^{g}$

\footnotetext{
${ }^{10}$ The unemployment rate is derived from the equality of the flow of workers into employment and the flow from employment to unemployment.
} 
given the utility distribution of job offers $F^{g}$. Then

$$
\begin{aligned}
l^{g}\left(v^{g}, F^{g}\right) & =\frac{d G^{g}\left(v^{g}\right)}{d F^{g}\left(v^{g}\right)}\left\{n^{g}-u^{g}\left(\bar{b} \mid F^{g}\right)\right\} \\
& =\frac{\kappa n^{g} K\left(v^{g}\right)}{\left\{1+\kappa\left[1-F^{g}\left(v^{g}\right)\right]\right\}^{2}},
\end{aligned}
$$

if $F^{g}$ is continuous (see the appendix for derivation), and $l^{g}\left(v^{g}, F^{g}\right)$ is increasing on the support of $F^{g}$. An employer offers a higher job value to increase firm size in the steady state. The positive correlation between job value and firm size occurs for two reasons. First, higher utility makes a job more attractive to currently unemployed workers. This phenomenon is known as the Albrecht and Axell (1984) mechanism because workers are heterogeneous in their reservation utilities. Second, a higher job value attracts currently employed workers, which prevents them from taking another job; this phenomenon is called the Burdett-Mortensen channel.

\section{Equilibrium Distribution of Job Offers}

Conditional on the job packages offered by all other employers and on the search behaviors of men and women, each employer posts a tied-salary/hours offer that maximizes its steady-state profit (or utility) flow. In the case of employer discrimination, the employer's steady-state utility given the tied-salary/hours offer is expressed as: $\left[\rho_{j}(H)-S\right] l^{m}\left(v^{m}, F^{m}\right)$ for men and $\left[\rho_{j}(H)-S-d^{E R}\right] l^{f}\left(v^{f}, F^{f}\right)$ for women. The maximization problem is,

$$
\pi_{j}=\max _{(S, H)}\left[\rho_{j}(H)-S\right] l^{m}\left(v^{m}, F^{m}\right)+\left[\rho_{j}(H)-S-d^{E R}\right] l^{f}\left(v^{f}, F^{f}\right),
$$

for all jobs. ${ }^{11}$

\section{The Algorithm Used to Solve for the Distribution of the Tied-Salary/Hours Offer}

I solve for the model described above numerically because the equilibrium distribution of job values $F^{g}$ does not have a closed form solution, as in Burdett and Mortensen (1998) or Bontemps et al. (1999). The equilibrium distribution of job values $F^{g}$ is not known a priori because $F^{g}$ is determined endogenously by the distribution of salaries $S$ and hours $H$ across the population (for which I solve). Because the objective function is unlikely to be globally concave in the two choice variables, the direct approach to the problem is to perform

\footnotetext{
${ }^{11}$ For the case without discrimination, eliminate the disamenity value $d^{E R}$ in Equation (3). For the case of employee discrimination, the female utility is subtracted by the term $d^{E E}(\theta)$.
} 
a grid search, whose computation is extremely expensive. To ease the computation of $F^{g}, \mathrm{I}$ introduce a computationally and economically intuitive algorithm that is a good first guess for the solution. The idea is to take the economically intuitive salary-hour combinations as the starting points and solve for the maxima that converge from these starting points.

Step 1: Initialization Points. Because men and women have different preferences concerning hours, profit- (or utility-) maximizing employers post a salary-hour combination that considers the differences in gender preferences and the mix of men and women who would typically choose their jobs. Therefore, hours of work are first determined such that the marginal productivity of an hour equals the weighted average of the marginal disutility of an hour for men and women, where the weights reflect the gender composition of the particular job type in equilibrium. Let $\theta_{j}^{*}$ be the fraction of men working in a type- $j$ job in equilibrium. Then $H_{j}$ solves

$$
\rho_{j}^{\prime}(H)+\left[\theta_{j}^{*} \xi^{m} \phi^{\prime}(H)+\left(1-\theta_{j}^{*}\right) \xi^{f} \phi^{\prime}(H)\right]=0 .
$$

Using the functional forms for $v^{g}\left(S, H ; \xi^{g}\right)$ and $\rho_{j}(H)$ that are given in Equations (1) and (2), the hours are determined as

$$
H_{j}^{*}=T-\left(\frac{\theta_{j}^{*} \xi^{m}+\left(1-\theta_{j}^{*}\right) \xi^{f}}{2 a_{j}}\right)^{1 / 3}
$$

Next, the salary is chosen to maximize the steady-state profit (or utility) flow given $H_{j}^{*}$ and $\theta_{j}^{*}:$

$\pi_{j}=\max _{\{S\}}\left(\rho_{j}\left(H_{j}^{*}\right)-S\right) l^{m}\left(S+\xi^{m} \phi\left(H_{j}^{*}\right), F^{m}\right)+\left(\rho_{j}\left(H_{j}^{*}\right)-S-d^{E R}\right) l^{f}\left(S+\xi^{f} \phi\left(H_{j}^{*}\right), F^{f}\right)$.

The algorithm used to solve for the initialization distribution of $(S, H)$ first chooses initial guesses for $S^{0}$ and $\theta^{0}$. Hours $H^{0}$ are then computed using Equation (4). Given the distributions of $S^{0}$ and $H^{0}$, the distributions of the job values $F^{g}\left(v^{g}\right)$ and the fraction of men working in jobs $\theta^{1}=\frac{l^{m}\left(v^{m}, F^{m}\right)}{l^{m}\left(v^{m}, F^{m}\right)+l^{f}\left(v^{f}, F^{f}\right)}$ are derived. Then salary $S^{1}$ is obtained using the first-order condition of Equation (5). Given the updated distributions of $\left(S^{1}, \theta^{1}\right)$, I again compute the hours $H^{1}$ by using Equation (4). This procedure is continued until $\left(S, H, F^{g}\right)$ converges.

Step2: Newton Method. In determining the hours in Equation (4), the difference in turnover behavior between men and women was not considered, although employers are 
likely to place greater value on workers who remain in the job longer. Therefore, the solution derived in Step 1 may not be optimal.

The second step of the algorithm performs a Newton method on the $H$ variable. Starting from the salary-hour combinations derived in Step 1, I solve for the salary-hour combinations that satisfy the first-order conditions for local maxima in Equation (3):

$$
\frac{\partial \pi_{j}}{\partial S}=0 \text { and } \frac{\partial \pi_{j}}{\partial H}=0 \text { for all } j
$$

and, the second-order condition that implies that the Hessian matrix is a negative definite:

$$
\frac{\partial^{2} \pi_{j}}{\partial S^{2}}<0, \frac{\partial^{2} \pi_{j}}{\partial H^{2}}<0 \text {, and } \frac{\partial^{2} \pi_{j}}{\partial S^{2}} \frac{\partial^{2} \pi_{j}}{\partial H^{2}}-\left[\frac{\partial^{2} \pi_{j}}{\partial S \partial H}\right]^{2}>0 \text { for all } j .
$$

In particular, I first update hours by $H^{k+1}=H^{k}+\psi \frac{\partial \pi}{\partial H^{k}}$, where $\psi$ is the negative of the inverse of the second-order derivative. Given the salary and the updated hours, I solve for the distributions of the job values $F^{g}\left(v^{g}\right)$ and employment size $l^{g}\left(v^{g}, F^{g}\right)$. Then salary $S$ is derived using the first-order condition with respect to $S$ in Equation (3). Hours are again updated by $H^{k+1}=H^{k}+\psi \frac{\partial \pi}{\partial H^{k}}$. This procedure is repeated until $\left(S, H, F^{g}\right)$ converges and all jobs satisfy the first- and second-order conditions for Equation (3).

To examine whether the solution derived with this two-step algorithm is the best one, I take various initialization points and use the Newton method in Step 2 to solve for $(S, H)$. In cases when the initial hours and salary distributions are chosen to increase with job productivity and the second-order derivative with respect to hours remains negative during the iteration process, the salary-hours bundles converge to the same solutions as the two-step algorithm. However, others do not converge to satisfy the profit (or utility) maximization conditions of Equation (3). Therefore, the advantage of using the two-step algorithm is that the algorithm produces optimal solutions in a short amount of time.

\section{Simulation}

This section presents simulation results comparing three cases: (1) a baseline case without discrimination, (2) a case of employer discrimination, and (3) a case of employee discrimination.

\section{Baseline Case without Discrimination}

The parameter values in the baseline simulation are specified as follows: 


\begin{tabular}{clc}
\hline Parameter & \multicolumn{1}{c}{ Description } & Value \\
\hline$n^{m}$ & Number of men & 0.5 \\
$n^{f}$ & Number of women & 0.5 \\
$\xi^{m}$ & Men's hours preference & 3000 \\
$\xi^{f}$ & Women's hours preference & 60000 \\
$b$ & Reservation utility & $N\left(-1500,1000^{2}\right)$ \\
$a_{j}$ & Technology parameter & $0.1 \leq a_{j} \leq 0.2$ \\
$\kappa$ & Ratio of job offer arrival rate to job separation rate $=\lambda / \delta$ & 3 \\
$T$ & Upper limit on hours worked & 70 \\
\hline
\end{tabular}

There is an equal number of men and women in the population: $n^{m}=n^{f}=0.5$. Because the preference parameters satisfy $\xi^{m}<\xi^{f}$, women are more averse to long work hours than men. The distribution of reservation utility $b$ is normal, with a mean of -1500 and a standard deviation of 1000. The technology parameter $a_{j}$ is Pareto distributed. ${ }^{12}$ The equilibrium solutions are represented by the solid lines in Figure 1. Table 1, column 1 displays the equilibrium outcomes for the selected jobs: the least productive job, where the technology parameter is $a_{j}=0.1$; the mid-productive job, where the technology parameter is $a_{j}=0.15$; and the most productive job, where the technology parameter is $a_{j}=0.2$.

As presented in Table 1, column 1 and illustrated by a solid line in Figure 1, men place greater value on higher-productivity jobs that pay greater salaries and require longer working hours. Conversely, women place lower value on these types of jobs because they are more averse to long working hours. Twenty-six percent of women never work (i.e., never participate in the labor force) because their reservation utility is greater than the utility derived from all jobs. $^{13}$

Because of the presence of search frictions, jobs are not completely segregated by gender. The fraction of men working in jobs increases with job productivity from $\theta=0.0783$ to 0.9846 . Men quit and move to more productive jobs, and few women work in these jobs. The labor supply elasticity $\frac{\partial l^{g} / l^{g}}{\partial S / S}$ is positive and is greater for men than for women in these higherproductivity jobs. This finding implies that men are more sensitive to hours than women in the change in salaries of higher-productivity jobs and that employers tailor their offers to men's hours preferences. Consequently, women quit for shorter working-hour jobs, and a high proportion of women (75.5 percent) prefer to remain unemployed rather than accept higher-productivity jobs. In contrast, in lower-productivity jobs, the labor supply elasticity is greater for women than for men, and women are more sensitive than men to hours for the

\footnotetext{
${ }^{12}$ The probability density function of the technology parameter is $\frac{2.8 \times 3000^{2.8}}{3000+\left(a_{j}-0.1\right) \times 50000}$, which is defined over the interval $a_{j} \geq 0.1$. In the simulation, one hundred jobs are chosen at regular intervals along the segment $a_{j}=[0.1,0.2]$, and the equilibrium job offer is derived for each of these jobs.

${ }^{13}$ The corresponding number for men is 1.75 percent.
} 
change in the salary. Thus, employers' offers are tailored toward women's hours preferences.

\section{The Case of Employer Discrimination}

To study discrimination in an environment that has gender asymmetries in hours preferences, I use the parameter values in the baseline case and set the discrimination parameter as $d^{E R}=20$. The results are represented by the dotted lines in Figure 1. For the selected jobs, the results are presented in Table 1, column 2.

Employers suffer a loss in utility of $d^{E R}$ by hiring women. Constrained to post only one offer for both men and women, employers make their offers unappealing to women by requiring more working hours while not considerably increasing the salary. As the job value for women declines, women with a higher reservation utility prefer to remain unemployed rather than work in these types of jobs. Therefore, the number of females employed in the job declines. Men, in contrast, seldom leave their jobs. As a result, the fraction of men working in the job increases. This increase is modest because the job offers have already been tailored toward men's preferences in the baseline case without discrimination.

\section{The Case of Employee Discrimination}

Finally, I consider a case where women incur a disutility from working in jobs with more men but derive a positive utility from working in jobs with more women. The discrimination parameter is set as $d^{E E}(\theta)=500\left(\theta-\frac{1}{2}\right)$, and all other parameter values are taken from the baseline case. The equilibrium solutions are represented by the dotted lines in Figure 2 and are presented for the selected jobs in Table 1, column 3.

As illustrated in Figure 2 (dotted line), women suffer a utility loss from working in higherproductivity jobs with high hours requirements and a large proportion of men. Some women choose to be unemployed rather than work in these types of jobs. The number of women employed in these jobs drops, and the fraction of men employed increases. Compared with the baseline case, these employers realize less profit because attractive job packages must be offered to maintain employee numbers.

Meanwhile, the utility of work for women increases in lower-productivity jobs. Women prefer reduced working hours and the presence of more women in the working environment. The fraction of men decreases slightly. Employers obtain a higher profit compared with the baseline case because women attain a higher utility without incurring further costs. Specifically, in the least productive jobs (where the technology parameter is $a_{j}=0.1$ ), the utility that 
women derive from only the tied-salary/hours package is $-858.06\left(=S+\xi^{f} \phi(H)\right)$ (which is almost equivalent to the utility women derive in the baseline case, -858.08), but the actual utility that women receive is higher because $v^{f}=S+\xi^{f} \phi(H)-d^{E E}(\theta)=-664.32$.

\section{Concluding Remarks}

In this paper, I analyze an equilibrium search model where salary and working hours are job attributes, and men and women differ in their working-hour preferences. In particular, women are more averse to longer work hours than men. Every employer posts a single menu of salaries and working hours, which workers may accept or reject depending on their employment status. Because the equilibrium of this model does not admit closed-form solutions, I propose an algorithm to numerically solve for the equilibrium. The qualitative features of the equilibrium are studied via simulations.

The simulations indicate that employers with a larger marginal productivity of hours require more working hours. Women, who are more averse to longer work hours than men, predominate less-productive jobs, which offer fewer working hours and lower pay. If employers discriminate against women, these employers will require more working hours. This discrimination excludes women from their jobs. Employers can control the types of workers they hire by choosing to offer certain job amenities because different groups of workers tend to have different job amenity preferences.

If employee discrimination against women increases with the proportion of men working in the job, employers tailor their offers to the group from which they can hire more workers. Women place a smaller value on higher-productivity jobs because of the greater hours requirements and the disutility from the higher concentration of men. Conversely, women place a greater value on lower-productivity jobs because of the shorter hours and the amenity from the higher fraction of females. Consequently, higher-productivity jobs are tailored more toward men's preferences, and lower-productivity jobs are tailored more toward women's preferences. Therefore, segregation is reinforced.

Because the model yields empirical predictions regarding discrimination and gender differences in preferences, future researchers may calibrate the search model by using labor market survey data. It would be a challenging exercise to identify the discrimination and preference parameters, but this examination would enable us to answer the question of whether employers, employees, or neither group discriminates in the labor market. 
Appendix: Derivation of $l^{g}\left(v^{g}, F^{g}\right)$

$$
\begin{aligned}
l^{g}\left(v^{g}, F^{g}\right)= & \frac{d G^{g}\left(v^{g}\right)\left\{n^{g}-u^{g}\left(\bar{b} \mid F^{g}\right)\right\}}{d F^{g}\left(v^{g}\right)} \\
= & \frac{d G^{g}\left(v^{g}\right)\left\{n^{g}-u^{g}\left(\bar{b} \mid F^{g}\right)\right\}}{d v^{g}} \frac{d v^{g}}{d F^{g}\left(v^{g}\right)} \\
= & \frac{d v^{g}}{d F^{g}\left(v^{g}\right)} \cdot\left[\frac{\kappa \int_{\underline{b}}^{v^{g}} \frac{d F^{g}\left(v^{g}\right)}{d v^{g}} d u^{g}\left(x \mid F^{g}\right)\left\{1+\kappa\left[1-F^{g}\left(v^{g}\right)\right]\right\}}{\left\{1+\kappa\left[1-F^{g}\left(v^{g}\right)\right]\right\}^{2}}\right. \\
& \left.+\frac{\left.\kappa^{2} \frac{d F^{g}\left(v^{g}\right)}{d v^{g}} \int_{\underline{b}}^{v^{g}}\left[F^{g}\left(v^{g}\right)-F^{g}(x)\right] d u^{g}\left(x \mid F^{g}\right)\right]}{\left\{1+\kappa\left[1-F^{g}\left(v^{g}\right)\right]\right\}^{2}}\right] \\
= & \frac{\kappa \int_{\underline{b}}^{v^{g}}\left[1+\kappa\left[1-F^{g}(x)\right]\right] d u^{g}\left(x \mid F^{g}\right)}{\left\{1+\kappa\left[1-F^{g}\left(v^{g}\right)\right]\right\}^{2}} .
\end{aligned}
$$

Use $\left\{1+\kappa\left[1-F^{g}(x)\right]\right\} d u^{g}\left(x \mid F^{g}\right)=n^{g} d K(x)$, which is derived from the first steady-state condition. Then, $l^{g}\left(v^{g}, F^{g}\right)$ is simplified to,

$$
\begin{aligned}
l^{g}\left(v^{g}, F^{g}\right) & =\frac{\kappa \int_{\underline{b}}^{v^{g}} n^{g} d K(x)}{\left\{1+\kappa\left[1-F^{g}\left(v^{g}\right)\right]\right\}^{2}} \\
& =\frac{\kappa n^{g} K\left(v^{g}\right)}{\left\{1+\kappa\left[1-F^{g}\left(v^{g}\right)\right]\right\}^{2}} .
\end{aligned}
$$




\section{References}

[1] Albrecht, James W., and Bo Axell. 1984. "An Equilibrium Model of Search Unemployment." Journal of Political Economy 92(5), 824-40.

[2] Altonji, Joseph G., and Rebecca M. Blank. 1999. "Race and Gender in the Labor Market." in Orley Ashenfelter and David Card, eds., Handbook of Labor Economics, Vol. 3C (Amsterdam: Elsevier Science), 3143-259.

[3] Altonji, Joseph G., and Christina H. Paxson. 1986. "Job Characteristics and Hours of Work." in Ronald G. Ehrenberg, ed., Research in Labor Economics, Vol. 8, Part A (Greenwich: Westview Press), 1-55.

[4] Altonji, Joseph G., and Christina H. Paxson, 1988. "Labor Supply Preferences, Hours Constraints, and Hours-Wage Trade-offs." Journal of Labor Economics 6(2), 254-76.

[5] Becker, Gary S. 1971. The Economics of Discrimination. (Chicago, IL: the University of Chicago Press).

[6] Black, Dan A. 1995. "Discrimination in an Equilibrium Search Model." Journal of Labor Economics 13(2), 309-34.

[7] Bontemps, Christian, Jean-Marc Robin, and Gerard J. van den Berg. 1999. "An Empirical Equilibrium Job Search Model with Search on the Job and Heterogenous Workers and Firms." International Economics Review 40(4), 1039-74.

[8] Bowlus, Audra J., and Zvi Eckstein. 2002. "Discrimination and Skill Differences in an Equilibrium Search Model." International Economic Review 43(4), 1309-46.

[9] Burdett, Kenneth, and Dale T. Mortensen. 1998. "Wage Differentials, Employer Size, and Unemployment." International Economic Review 39(2), 257-73.

[10] Bergmann, Barbara R. 1974. "Occupational Segregation, Wages and Profits When Employers Discriminate by Race or Sex." Eastern Economic Journal 1, 103-10.

[11] Flabbi, Luca. 2010. "Gender Discrimination Estimation in a Search Model with Matching and Bargaining." International Economic Review 51(3), 745-83. 
[12] Gneezy, Uri, Muriel Niederle, and Aldo Rustichini. 2003. "Performance in Competitive Environments: Gender Differences." Quarterly Journal of Economics 118(3), 1049-74.

[13] Ham, John C. 1982. "Estimation of a Labor Supply Model with Censoring Due to Unemployment and Underemployment." Review of Economic Studies 49(3), 335-54.

[14] Ham, John C. 1986. "Testing Whether Unemployment Represents Life-Cycle Labor Supply." Review of Economic Studies 53(3), 559-78.

[15] Hwang, Hae-shin, Dale T. Mortensen and W. Robert Reed. 1998. "Hedonic Wages and Labor Market Search.” Journal of Labor Economics 16(4), 815-47.

[16] Johnson, George E., and Frank P. Stafford. 1998. "Alternative Approaches to Occupational Exclusion." in Inga Persson and Christina Jonung, eds., Women's Work and Wages (New York, NY: Routledge), 72-88.

[17] Kahn, Shulamit B., and Kevin Lang. 1995. "The Causes of Hours Constraints: Evidence from Canada." Canadian Journal of Economics 28(4a), 914-28.

[18] Kahn, Shulamit B., and Kevin Lang. 1991. "The Effects of Hours Constraints on Labor Supply Estimates." Review of Economics and Statistics 73(4), 605-11.

[19] Lang, Kevin, and Shulamit B. Kahn. 2001. "Hours Constraints." in Garnett Picot and Ging Wong, eds., Working Time in Comparative Perspective, Vol. I (Kalamazoo, MI: Upjohn Institute), 261-90.

[20] Lang, Kevin, and Sumon Majumdar. 2004. "The Pricing of Job Characteristics When Markets do Not Clear: Theory and Policy Implications." International Economics Review $45(4), 1111-28$.

[21] Rosen, Sherwin. 1974. "Hedonic Prices and Implicit Markets: Product Differentiation in Pure Competition." Journal of Political Economy 82(1), 34-55.

[22] Senesky, Sarah. 2005. "Testing the Intertemporal Labor Supply Model: Are Jobs Important?" Labour Economics 12(6), 749-72.

[23] Usui, Emiko. 2002. Gender Occupational Segregation: Theory and Evidence, Diss. Northwestern University. 
[24] Usui, Emiko. 2008. "Job Satisfaction and the Gender Composition of Jobs." Economics Letters 99(1), 23-6.

[25] Usui, Emiko. 2009. "Wages, Non-Wage Characteristics, and Predominantly Male Jobs." Labour Economics 16(1), 52-63. 
TABLE 1

Summary of results for the simulation

\begin{tabular}{|c|c|c|c|c|}
\hline & & Baseline Case & $\begin{array}{c}\text { Employer } \\
\text { Discrimination }\end{array}$ & $\begin{array}{c}\text { Employee } \\
\text { Discrimination }\end{array}$ \\
\hline & & $\begin{array}{c}\text { Figures } 1 \& 2 \\
\text { (solid line) }\end{array}$ & $\begin{array}{c}\text { Figure } 1 \\
\text { (dotted line) } \\
\end{array}$ & $\begin{array}{c}\text { Figure } 2 \\
\text { (dotted line) } \\
\end{array}$ \\
\hline & Job & (1) & (2) & (3) \\
\hline \multirow{3}{*}{ Job value for men, $v^{m}$} & Low & -0.71 & 12.51 & -1.16 \\
\hline & Mid & 473.91 & 475.71 & 475.54 \\
\hline & High & 608.27 & 608.27 & 608.87 \\
\hline \multirow[t]{3}{*}{ Job value for women, $v^{f}$} & Low & -858.08 & -880.60 & -644.32 \\
\hline & Mid & -1880.29 & -2001.90 & -2176.56 \\
\hline & High & -2190.54 & -2206.94 & -2463.07 \\
\hline \multirow[t]{3}{*}{ Salary, S } & Low & 44.41 & 59.52 & 43.94 \\
\hline & Mid & 597.81 & 606.11 & 602.91 \\
\hline & High & 755.57 & 756.44 & 757.67 \\
\hline \multirow[t]{3}{*}{ Hours of work, $H$} & Low & 3.52 & 6.18 & 3.48 \\
\hline & Mid & 45.79 & 46.99 & 46.45 \\
\hline & High & 49.63 & 49.75 & 49.84 \\
\hline \multirow[t]{3}{*}{ Fraction of men working in jobs, $\theta$} & Low & 0.0783 & 0.0792 & 0.0725 \\
\hline & Mid & 0.9504 & 0.9564 & 0.9644 \\
\hline & High & 0.9846 & 0.9849 & 0.9894 \\
\hline \multirow[t]{3}{*}{ Number of men employed, $I^{\mathrm{m}}$} & Low & 0.0943 & 0.0945 & 0.0943 \\
\hline & Mid & 0.7757 & 0.7758 & 0.7758 \\
\hline & High & 1.4737 & 1.4737 & 1.4738 \\
\hline \multirow[t]{3}{*}{ Number of women employed, $I^{f}$} & Low & 1.1093 & 1.0983 & 1.2059 \\
\hline & Mid & 0.0405 & 0.0354 & 0.0287 \\
\hline & High & 0.0230 & 0.0225 & 0.0158 \\
\hline
\end{tabular}

Notes: The table displays the outcomes (in the row headings) for the least productive jobs (labeled Low, $a_{\text {Low }}=0.1$ ), the midproductive jobs (Mid,$a_{\text {Mid }}=0.15$ ), and the most productive jobs (High, $\left.a_{\text {High }}=0.2\right)$. The job value is $v^{g}=S-\xi^{g} /(T-H)$, where $S$ is salary, $H$ is hours of work, and $T=70$. Hours preference parameters are $\xi^{\mathrm{m}}=3,000$ and $\xi^{\dagger}=60,000$. Discrimination coefficients are $d^{\mathrm{ER}}=20$ and $d^{\mathrm{EE}}(\theta)=500(\theta-1 / 2)$, where $\theta$ is the fraction of men working in jobs. 
FIGURE 1

Comparison between the baseline case and the case of employer discrimination

(a): Utility of a job for men and women
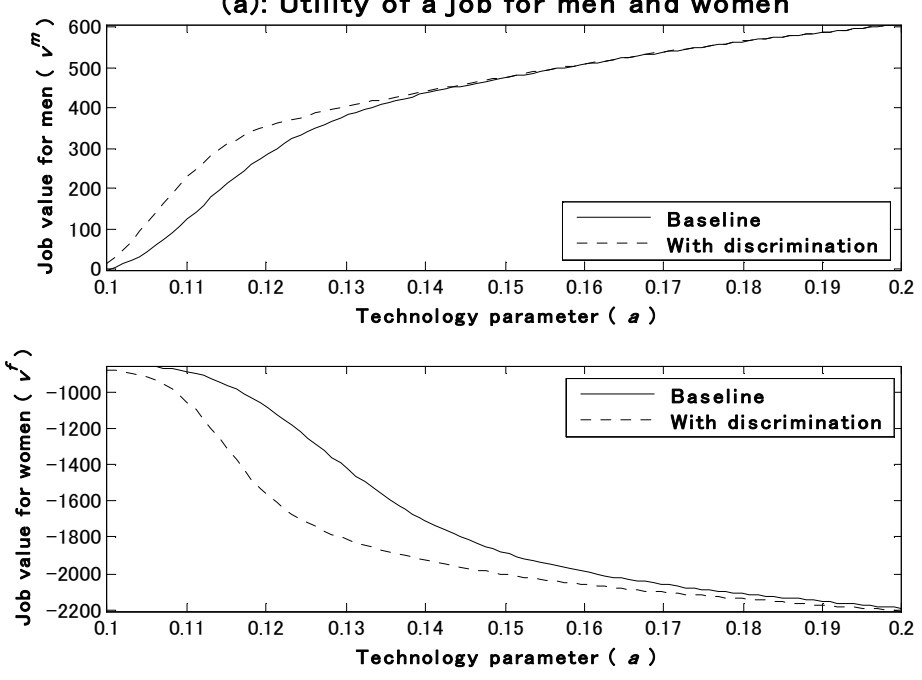

(c): Proportion of men working in jobs: $\theta$

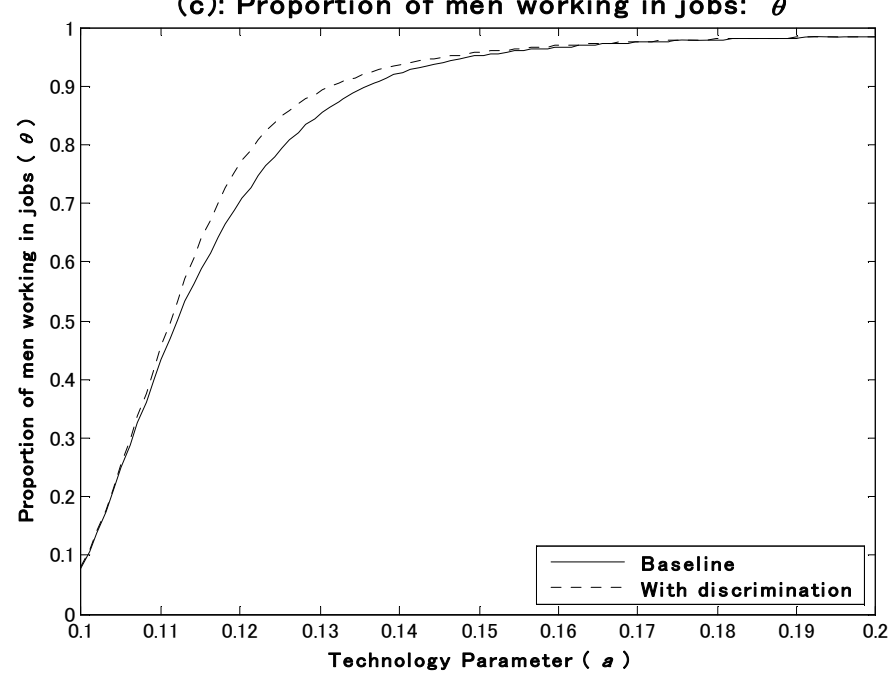

(b): Salary and hours of work

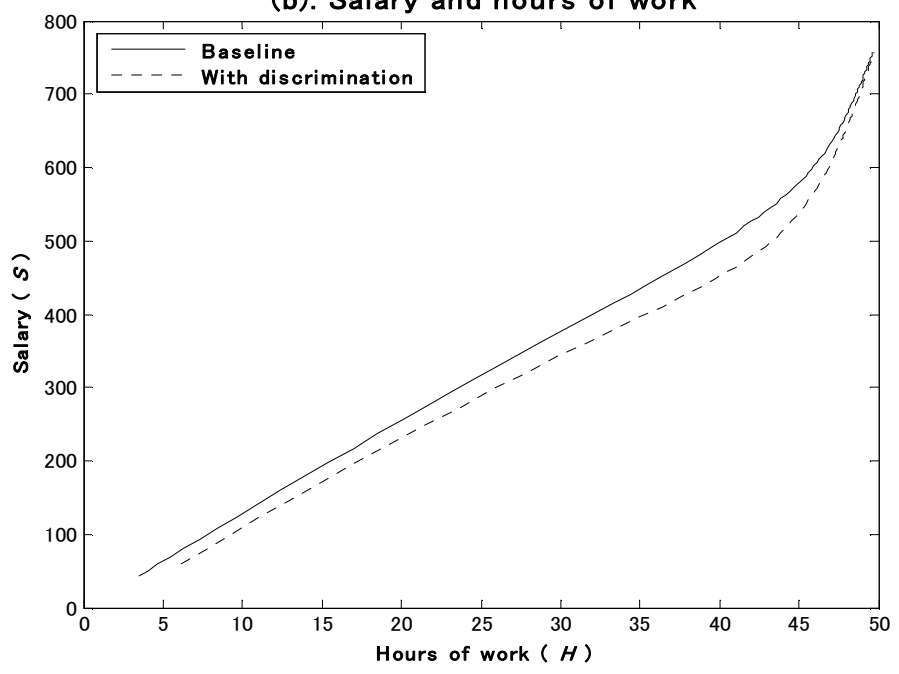

(d): Difference in employment size $\mathrm{w} /$ and w/o discrimination

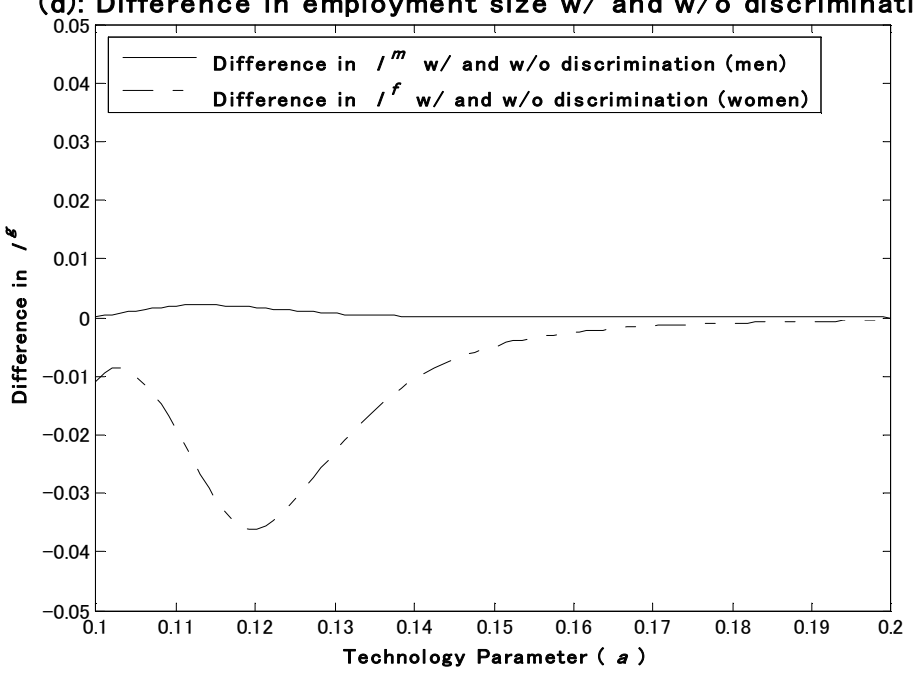


FIGURE 2

Comparison between the baseline case and the case of employee discrimination

(a): Utility of a job for men and women
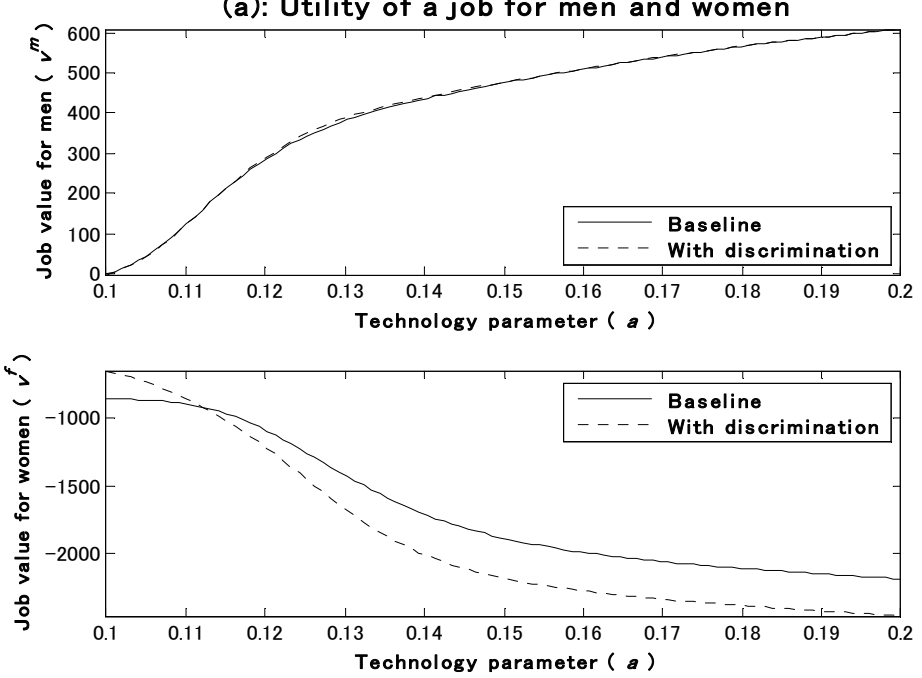

(c): Proportion of men working in jobs:

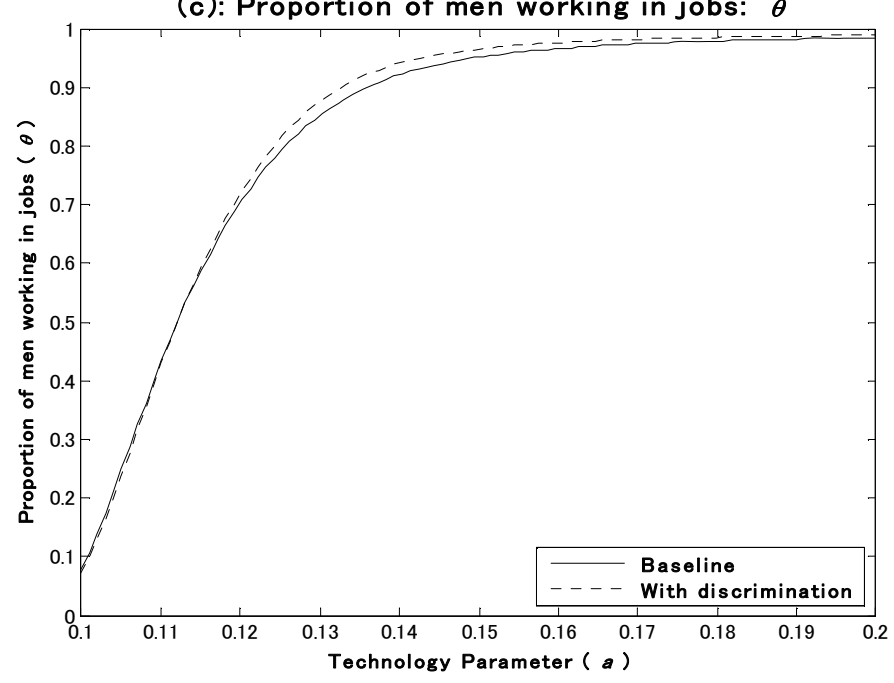

(b): Salary and hours of work

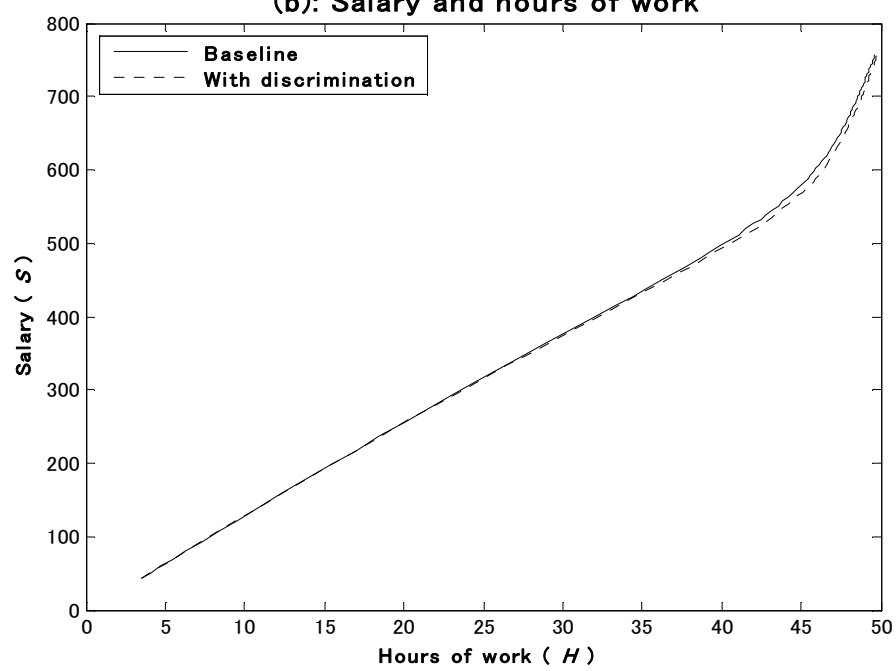

(d): Difference in employment size w/ and w/o discrimination

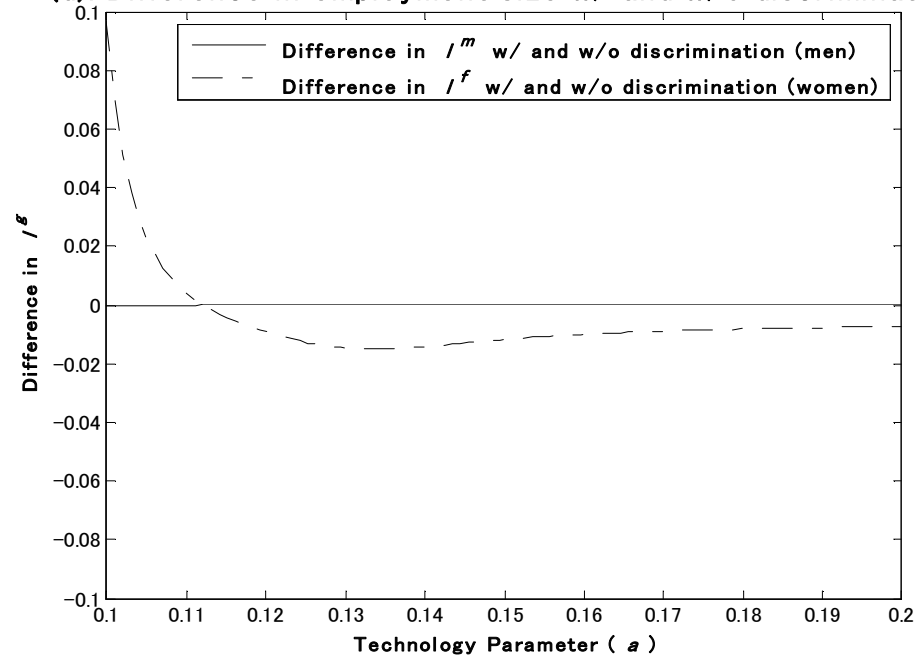

